\title{
Article
}

\section{Cold Atmospheric Plasma Modification of Amyloid $\beta$}

\author{
Maho Yagi-Utsumi ${ }^{1,2} \mathbb{D}_{\text {, Tomohiro Tanaka }}{ }^{1,3,4}(\mathbb{D})$, Yoko Otsubo ${ }^{4,5,6} \mathbb{D}$, Akira Yamashita ${ }^{4,5}$, \\ Shinji Yoshimura $4,6,7$, Motohiro Nishida $1,3,4$ (D) and Koichi Kato ${ }^{1,2, *(\mathbb{D})}$
}

1 Exploratory Research Center on Life and Living Systems (ExCELLS), National Institutes of Natural Sciences, Okazaki, Aichi 444-8787, Japan; mahoyagi@ims.ac.jp (M.Y.-U.); ttanaka@nips.ac.jp (T.T.); nishida@nips.ac.jp (M.N.)

2 Institute for Molecular Science (IMS), National Institutes of Natural Sciences, Okazaki, Aichi 444-8787, Japan

3 National Institute for Physiological Sciences, National Institutes of Natural Sciences, Okazaki, Aichi 444-8787, Japan

4 Department of Plasmabio Science, Center for Novel Science Initiatives, National Institutes of Natural Sciences, Minato-ku, Tokyo 105-0001, Japan; otsubo@nibb.ac.jp (Y.O.); ymst@nibb.ac.jp (A.Y.); yoshimura.shinji@nifs.ac.jp (S.Y.)

5 National Institute for Basic Biology, National Institutes of Natural Sciences, Okazaki, Aichi 444-8585, Japan

6 National Institute for Fusion Science, National Institutes of Natural Sciences, Toki, Gifu 509-5292, Japan

7 Center for Low-temperature Plasma Sciences, Nagoya University, Nagoya 464-8601, Japan

* Correspondence: kkatonmr@ims.ac.jp; Tel.:+81-564-59-5225

Citation: Yagi-Utsumi, M.; Tanaka,

T.; Otsubo, Y.; Yamashita, A.;

Yoshimura, S.; Nishida, M.; Kato, K Cold Atmospheric Plasma Modification of Amyloid $\beta$. Int. J. Mol. Sci. 2021, 22, 3116. https:// doi.org/10.3390/ijms22063116

Academic Editor: Vytautas Smirnovas

Received: 14 February 2021

Accepted: 16 March 2021

Published: 18 March 2021

Publisher's Note: MDPI stays neutral with regard to jurisdictional claims in published maps and institutional affiliations.

\begin{abstract}
Cold atmospheric plasma (CAP) has attracted much attention in the fields of biotechnology and medicine owing to its potential utility in clinical applications. Recently accumulating evidence has demonstrated that CAP influences protein structures. However, there remain open questions regarding the molecular mechanisms behind the CAP-induced structural perturbations of biomacromolecules. Here, we investigated the potential effects of CAP irradiation of amyloid $\beta$ (A $\beta$ ), an amyloidogenic protein associated with Alzheimer's disease. Using nuclear magnetic resonance spectroscopy, we observed gradual spectral changes in A $\beta$ after a 10 s CAP pretreatment, which also suppressed its fibril formation, as revealed by thioflavin $\mathrm{T}$ assay. As per mass spectrometric analyses, these effects were attributed to selective oxidation of the methionine residue (Met) at position 35. Interestingly, this modification occurred when $A \beta$ was dissolved into a pre-irradiated buffer, indicating that some reactive species oxidize the Met residue. Our results strongly suggest that the $\mathrm{H}_{2} \mathrm{O}_{2}$ generated in the solution by CAP irradiation is responsible for Met oxidation, which inhibits $A \beta$ amyloid formation. The findings of the present study provide fundamental insights into plasma biology, giving clues for developing novel applications of CAP.
\end{abstract}

Keywords: amyloid $\beta$; cold atmospheric plasma; hydrogen peroxide; NMR

\section{Introduction}

Cold atmospheric plasma (CAP) has been widely used across the industrial fields as exemplified by sterilization and surface fabrication. Recently, CAP has attracted much attention in the biotechnology and medical fields [1,2]. Various studies have been conducted on the effect of non-thermal plasmas for wound healing, blood coagulation, skin regeneration, and action against cancer cells [3]. Therefore, it is of great interest and importance to elucidate how the structures, motions, and associations of biomacromolecules are affected by plasma irradiation from the perspective of plasma biology and biomolecular science. In a recent series of pioneering studies, Lee and coworkers investigated the effects of $\mathrm{CAP}$ on the biomolecular structures using various globular proteins, including myoglobin, hemoglobin, and lysozyme, as well as amino acids, as model molecules [4-7]. These data demonstrated that carbonylation occurs in protein due to reactive oxygen and nitrogen species generated by CAP, which induces changes in the secondary and/or tertiary structures of proteins. This is exemplified by the structural perturbation of lysozyme coupled 
with a modification of the tryptophane group in its substrate binding site [5]. In addition, plasma-induced chemical modifications of amino acids have been reported, including hydroxylation and nitration of aromatic rings in tyrosine, phenylalanine, and tryptophan, sulfonation and disulfide linkage formation of thiol groups in cysteine, sulfoxidation of methionine, and amidation and ring-opening of five-membered rings in histidine and proline $[4,8]$. In addition, Bayliss et al. reported that amyloid fibrils can be degraded by CAP treatment [9]. Although these CAP effects have been ascribed to some chemical modifications, there remain open questions regarding the molecular mechanisms behind the observed phenomena.

Considering its clinical importance, the molecular mechanisms underlying the assembly of amyloid- $\beta(A \beta)$, which is associated with Alzheimer's disease, have been extensively investigated through NMR spectroscopy, electron microscopy, computational simulation, and other biophysical techniques [10-20]. These studies indicated that the $A \beta$ amyloid formation processes and the consequent fibril morphology are strongly influenced by amino acid sequence modifications, such as familial mutations, as well as by solution environments, which includes ionic strength, $\mathrm{pH}$, temperature, pressure, and gravity as well as membrane environments. It is therefore intriguing to address the mechanisms of the effects of CAP on the $A \beta$ assembly.

In this study, we performed structural and kinetic analyses of amyloid fibril formation of the CAP-treated $A \beta$ protein. We attempted to identify $A \beta$ structural modifications caused by CAP irradiation and have discussed the possible mechanisms of the effects of CAP on amyloid formation.

\section{Results and Discussion}

\subsection{NMR Characterization of CAP-Treated $A \beta$}

We first examined the possible effects of CAP irradiation on A $\beta(1-40)$ structure. The $A \beta(1-40)$ solution was irradiated with moistened helium gas for $10 \mathrm{~s}$ using a plasma source (Figure 1). The structural changes before and after plasma irradiation were tracked using ${ }^{1} \mathrm{H}-{ }^{15} \mathrm{~N}$ heteronuclear single-quantum correlation (HSQC) peaks as spectroscopic probes (Figure 2 and Supplementary Materials Figure S1). Although no significant spectral change was observed immediately after CAP irradiation, the peaks originating from the segment from Ile32 to Val39, especially those from Met35 and Val36, gradually exhibited significant chemical shift changes after incubation at $37^{\circ} \mathrm{C}$ (i.e., from Met35 to Met35* and from Val36 to Val36*) (Figure 2c). The magnitudes in the spectral changes gradually reached a saturation point after the CAP irradiation and did not return to the original peak position (Figure 2c,e).

(a)

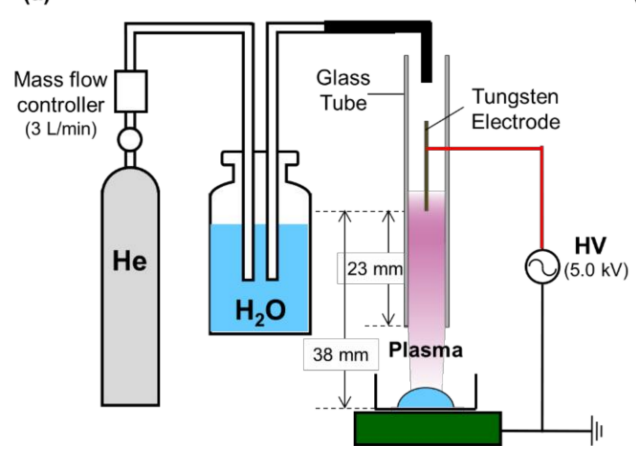

(b)

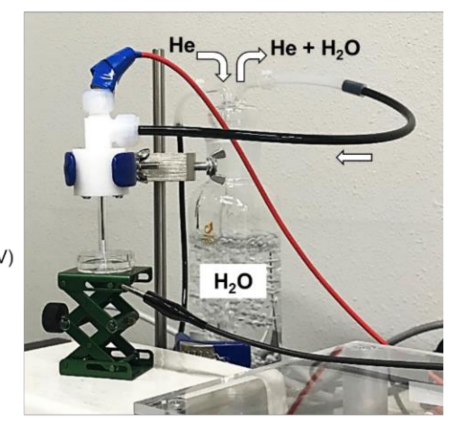

Figure 1. (a) Schematic illustration and (b) picture of the experimental setup for the helium atmospheric pressure plasma irradiation system primarily used in this study. In this $8.0 \mathrm{~W}$ plasma jet system, He gas passed through pure water and moist He with $100 \%$ relative humidity served as the source gas. The applied peak-to-peak voltage $(5.0 \mathrm{kV})$, the distance between the electrodes $(38 \mathrm{~mm})$, and the distance between the powered electrode and the edge of the glass tube $(23 \mathrm{~mm})$ were represented. 


\section{(a) $\stackrel{1}{\text { DAEFRHDSGYEVHHQKLVFFAEDVGSNKGAIIGLMVGGVV }} \stackrel{20}{20}$}

(b)

(c)

(d)

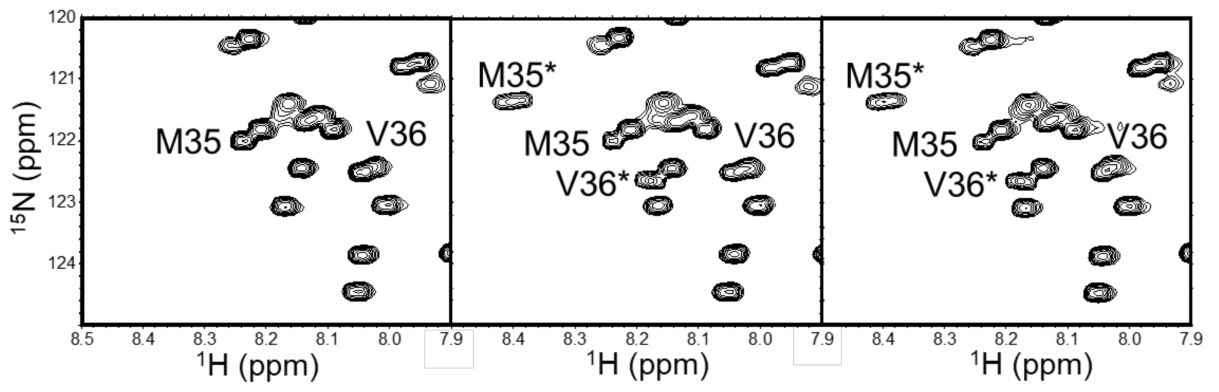

(e)

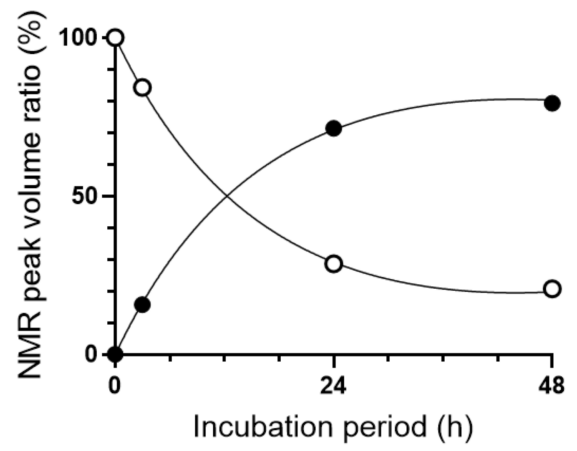

(f)

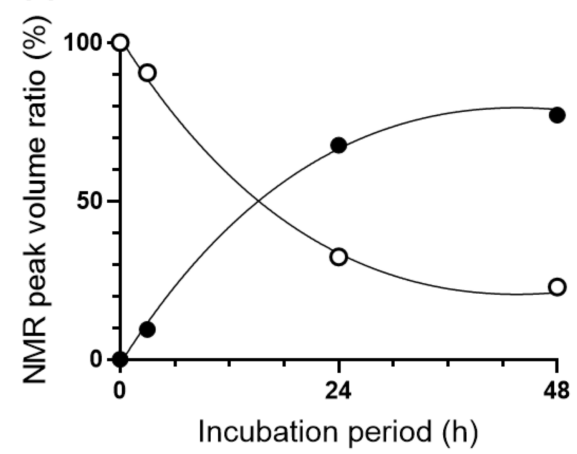

Figure 2. NMR spectral change of cold atmospheric plasma (CAP)-treated A $\beta$ (1-40). (a) The primary structure of $\mathrm{A} \beta(1-40)$ peptide. (b) A portion of ${ }^{1} \mathrm{H}-{ }^{15} \mathrm{~N}$ heteronuclear single-quantum correlation (HSQC) spectra of A $\beta$ (1-40) without irradiation. Portions of ${ }^{1} \mathrm{H}^{1}{ }^{15} \mathrm{~N}$ HSQC spectra of A $\beta$ (1-40) measured at $48 \mathrm{~h} \mathrm{(c)} \mathrm{after} \mathrm{a} 10 \mathrm{~s}$ irradiation of CAP or (d) after dissolving into the $10 \mathrm{~s}$ pre-irradiated buffer solution. The time course of NMR peak volume ratio of Met35 $\left({ }^{1} \mathrm{H} 8.2 \mathrm{ppm},{ }^{15} \mathrm{~N} 122.0 \mathrm{ppm}\right.$, open circle) and Met35* $\left({ }^{1} \mathrm{H} 8.4 \mathrm{ppm},{ }^{15} \mathrm{~N} 121.4 \mathrm{ppm}\right.$, closed circle) of $\mathrm{A} \beta(1-40)(\mathbf{e})$ after the $10 \mathrm{~s}$ irradiation of CAP or (f) after dissolving into the pre-irradiated buffer solution.

Similar spectral changes were also observed when A $\beta$ (1-40) was dissolved into the buffer solution immediately after buffer pretreatment with CAP (Figure $2 \mathrm{~d}, \mathrm{f}$ ). These observations suggest that the gradual structural modification of $A \beta(1-40)$ was not a consequence of direct plasma-protein interaction; rather, it was caused by some reactive species generated in the solution upon CAP irradiation.

\subsection{CAP Effects on A $\beta$ Fibril Formation}

We next examined whether plasma irradiation has any effects on $A \beta(1-40)$ fibril formation by investigating the time course of fibrilization with or without pretreatment of A $\beta$ (1-40) solution with CAP for $10 \mathrm{~s}$. The fibril growth was probed with the thioflavin $\mathrm{T}$ (ThT) dye, which specifically binds and colors amyloid fibrils. We noted that the plasma irradiation resulted in considerably slower progress in A $\beta$ (1-40) fibrilization (Figure 3). Generally, the amyloid fibrilization process consists of the nucleation and elongation phases. We noted that nucleation was delayed and that the fibril elongation rate also slowed down with increasing CAP irradiation time, which resulted in lower final fibril yield. These kinetic data suggest that the pre-irradiated $A \beta$ (1-40) formed significant amounts of nonfibril aggregates compared with the non-irradiated ones. We confirmed that the CAP irradiation suppresses the fibrilization of $A \beta(1-42)$ as well (Figure S2). 


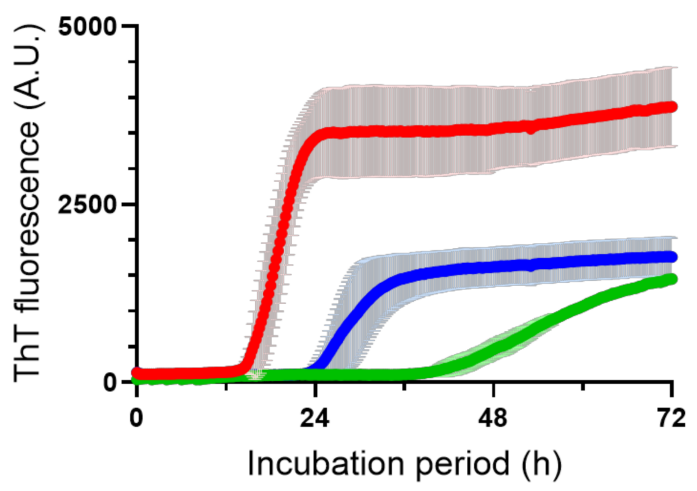

Figure 3. ThT fluorescence intensity profiles of the aggregation of $A \beta$ (1-40) without (red) and with CAP pretreatment for $10 \mathrm{~s}$ (blue) or $20 \mathrm{~s}$ (green). Each intensity value is the mean $\pm \mathrm{SD}$ of three values.

\subsection{Characterization of Chemical Modification of A $\beta$ Caused by CAP Treatment}

To identify the chemical modifications associated with the observed perturbation on $A \beta$ structure and assembly, the CAP-treated $A \beta(1-40)$ solutions were subsequently applied to reverse-phase HPLC and then analyzed by MALDI-TOF-MS and LC-MS/MS In the HPLC profiles, the $10 \mathrm{~s}$ plasma treatment gave rise to a new peak (peak-1) that eluted at $20.0 \mathrm{~min}$ with a concomitant reduction in the original peak (peak-2) at $21.1 \mathrm{~min}$ (Figure $4 \mathrm{a}-\mathrm{c}$ ). A $\beta(1-40)$ dissolved into the pre-irradiated buffer solution also exhibited peak-1 and peak-2 with a ratio of 8:2. Longer CAP irradiation resulted in an increase in the peak-1 intensity with a concomitant decrease in the peak-2 intensity (Figure 4d). MALDITOF-MS data showed that the molecular weights of A $\beta$ (1-40) proteins corresponding to peak- 1 and peak- 2 were 4592.6 and 4576.6 , respectively. Furthermore, the LC-MS/MS analysis revealed that the mass of Met35 increased by +16.0 upon CAP irradiation (Figure 5 and Supplementary Materials Table S1). These results indicated that the plasma irradiation resulted in selective oxidization of this methionine residue into methionine sulfoxide.

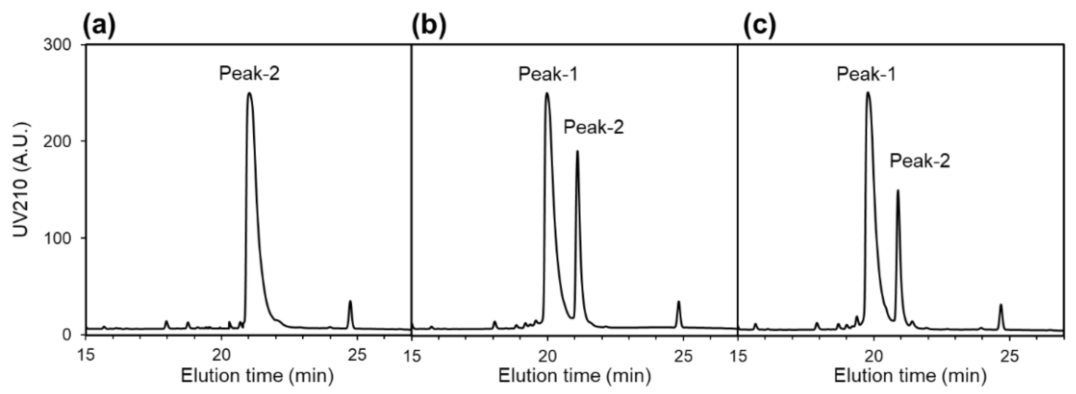

(d)

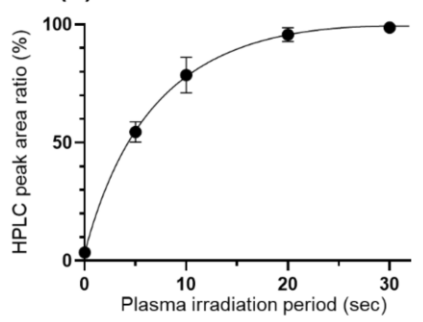

(e)

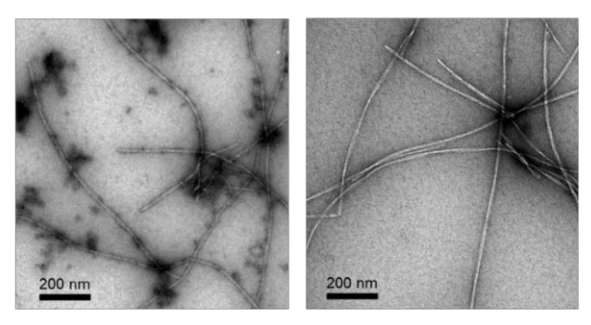

Figure 4. HPLC profiles of (a) A $\beta$ (1-40) without CAP treatment, (b) A $\beta$ (1-40) with 10 s CAP treatment, and (c) $A \beta(1-40)$ dissolved into the buffer solution pretreated with CAP. (d) Changes in the HPLC peak area ratio of peak-1 to peak-2 depending on the period of CAP irradiation. Each ratio value is the mean \pm SD of three values. (e) TEM images of amyloid fibrils prepared by A $\beta(1-40)$ in peak-1 (left panel) and in peak-2 (right panel) fractions. 


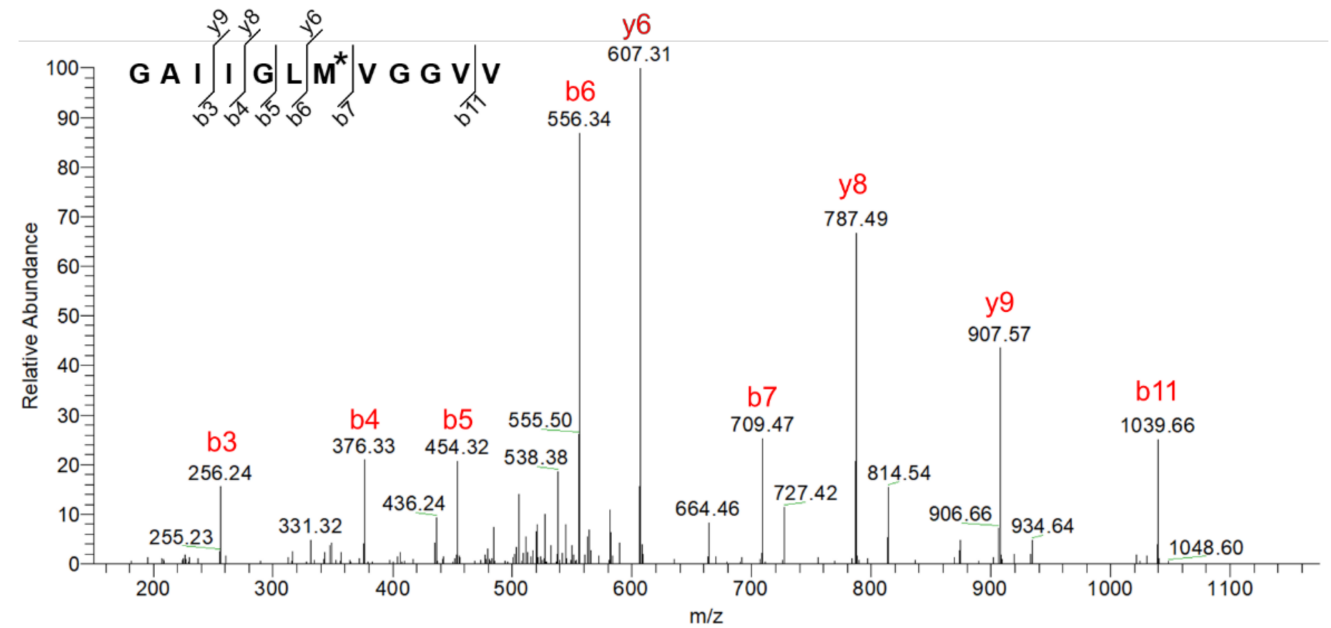

Figure 5. LC-MS/MS fragmentation profile of tryptic peptide of A $\beta$ (1-40) fraction corresponding to peak-1. $\mathrm{M}^{*}$ denotes oxidized Met.

Based on the ${ }^{1} \mathrm{H}-{ }^{15} \mathrm{~N}$ HSQC spectral data of the A $\beta$ (1-40) species corresponding to peak-1 and peak-2 (Figure S3), we confirmed that the aforementioned spectral changes, along with the changes in the fibril formation kinetics, caused by CAP treatment were ascribed exclusively to the formation of sulfoxide of Met35. Although transmission electron microscope (TEM) observation revealed no significant morphological difference in the mature fibrils formed from the $A \beta(1-40)$ species corresponding to the peak- 1 and peak-2 fractions, significant amounts of non-fibril aggregates were observed only in the specimens from the peak-1 fraction (Figure 4e). The accumulation of non-fibril aggregates is consistent with the lower level of final fibril yield, as probed with ThT (Figure 3). These data indicate that the Met35 oxidation prevented fibril formation.

\subsection{Reactive Species Responsible for Methionine Oxidation of A $\beta$}

We attempted to identify the putative reactive species causing the methionine oxidation of $A \beta(1-40)$. In fact, in the presence of $1 \mathrm{mM}$ ascorbic acid as a reducing reagent, virtually no HSQC spectral changes were observed for a CAP-treated A $\beta(1-40)$ solution (Figure $\mathrm{S} 1 \mathrm{~d}$ ). Various reactive oxygen species, including $\mathrm{H}_{2} \mathrm{O}_{2}$, are supposed to be produced upon water irradiation with CAP [21,22]. In the present study, we confirmed that $\mathrm{H}_{2} \mathrm{O}_{2}$ is generated by CAP irradiation in the buffer solution (Figures $\mathrm{S} 4$ and S5). We thus measured the ${ }^{1} \mathrm{H}-{ }^{15} \mathrm{~N}$ HSQC spectra of $\mathrm{A} \beta(1-40)$ in the presence of varying concentrations of $\mathrm{H}_{2} \mathrm{O}_{2}$, thereby demonstrating similar spectral changes to those observed in the $\mathrm{A} \beta(1-40)$ solution pre-irradiated with CAP (Figure $6 a, b)$. Based on the HPLC profiles, the levels of Met35 oxidation were quantified as a function of $\mathrm{H}_{2} \mathrm{O}_{2}$ concentration (Figure $6 c, d$ ). We also estimated the relationship between the Met35 oxidation level and the concentration of $\mathrm{H}_{2} \mathrm{O}_{2}$ generated by CAP irradiation using the two different apparatuses (Figure 6d). These data are quantitatively in good agreement. In addition, the NMR, TEM, and kinetics outcomes are largely consistent with the previously reported observations for $\mathrm{H}_{2} \mathrm{O}_{2}$-treated $A \beta$ proteins [23,24]. All these data cumulatively suggested that CAP-generated $\mathrm{H}_{2} \mathrm{O}_{2}$ induces methionine oxidation of $A \beta(1-40)$. As exemplified by its shorter retention time, A $\beta(1-40)$ with oxidized Met35 has less hydrophobic nature, which may hamper its fibrilization (Figure $4 \mathrm{~b}, \mathrm{c}$ ). Previously reported molecular dynamics simulation demonstrated that an $\mathrm{A} \beta$ pentamer is destabilized upon oxidation of Met35 due to lower inter-peptide binding free energy, resulting in a higher conformational flexibility with increasing solvent accessibility [25]. Indeed, we confirmed that the $A \beta(1-40)$ fibrils were degraded by incubation in the CAP-pretreated buffer as in the case of $\mathrm{H}_{2} \mathrm{O}_{2}$ treatment (Figure S6). Considering the findings obtained in this study, CAP-generated $\mathrm{H}_{2} \mathrm{O}_{2}$-induced degradation of $A \beta$ aggregates can also be ascribed to the Met 35 oxidation. 
(a)

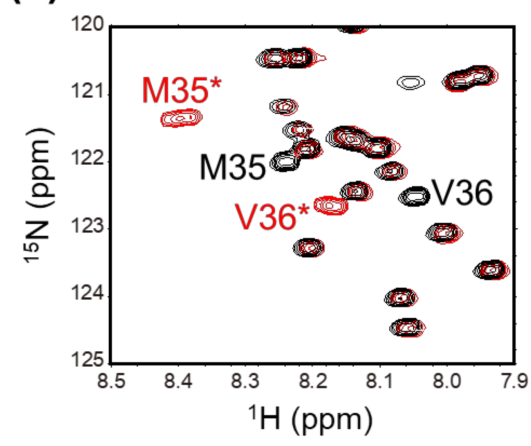

(c)

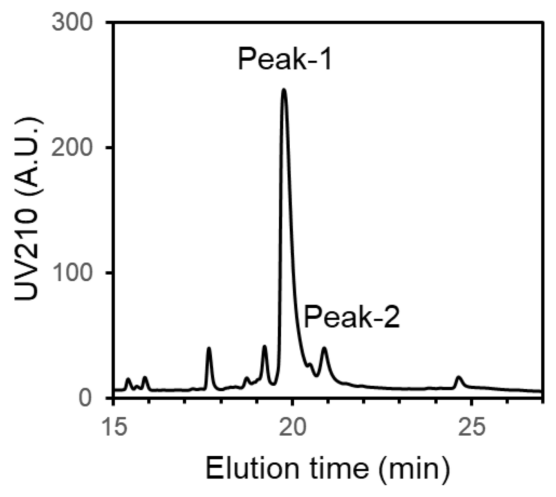

(b)

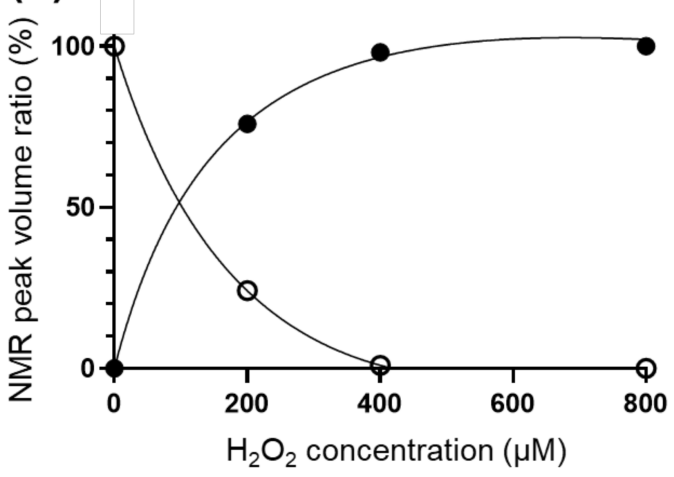

(d)

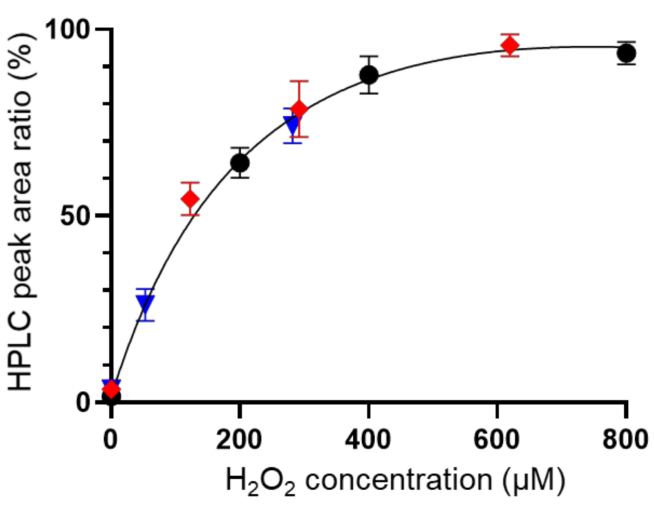

Figure 6. (a) The portions of ${ }^{1} \mathrm{H}-{ }^{15} \mathrm{~N}$ HSQC spectra of $\mathrm{A} \beta(1-40)$ in the absence (black) and presence (red) of $800 \mu \mathrm{M} \mathrm{H}_{2} \mathrm{O}_{2}$. The spectrum of $\mathrm{A} \beta$ (1-40) was measured at $24 \mathrm{~h}$ after $\mathrm{H}_{2} \mathrm{O}_{2}$ treatment. (b) Changes in the NMR peak volume ratio of Met35 $\left({ }^{1} \mathrm{H} 8.2 \mathrm{ppm},{ }^{15} \mathrm{~N} 122.0 \mathrm{ppm}\right.$, open circle) and Met35* $\left({ }^{1} \mathrm{H} 8.4 \mathrm{ppm},{ }^{15} \mathrm{~N} 121.4 \mathrm{ppm}\right.$, closed circle) of $\mathrm{A} \beta(1-40)$ depending on the $\mathrm{H}_{2} \mathrm{O}_{2}$ concentration. (c) HPLC profiles of $\mathrm{A} \beta$ (1-40) treated with $800 \mu \mathrm{M} \mathrm{H}_{2} \mathrm{O}_{2}$. (d) Changes in the HPLC peak area ratio of peak-1 to peak-2 depending on the $\mathrm{H}_{2} \mathrm{O}_{2}$ concentration. HPLC peak area ratios were plotted as a function of the $\mathrm{H}_{2} \mathrm{O}_{2}$ concentration used for the $\mathrm{A} \beta$ (1-40) treatment (black circle) along with those from the CAP irradiation experiments. For plotting, the CAP irradiation period was converted into the concentration of $\mathrm{H}_{2} \mathrm{O}_{2}$ generated in the buffer solution pretreated with CAP using $8.0 \mathrm{~W}$ and $1.0 \mathrm{~W}$ plasma jet apparatuses (according to the results shown in Figure S4 (red rhombus) and Figure $\mathrm{S} 5$ (blue triangle), respectively). Each ratio value is the mean $\pm \mathrm{SD}$ of three values.

\section{Materials and Methods}

\subsection{A $\beta$ Sample Preparation}

Bacterial expression and purification of isotopically labeled $A \beta(1-40)$ protein was performed as described previously [11]. Synthetic A $\beta$ (1-42) peptide was purchased from Toray Research Center, Inc. (Tokyo, Japan). A $\beta(1-40)$ was dissolved at an approximate concentration of $2 \mathrm{mM}$ in $0.1 \%(v / v)$ ammonia solution, followed by their collection and storage in aliquots at $-80^{\circ} \mathrm{C}$ until further use. Amyloid fibrils were prepared by incubation of $0.1 \mathrm{mM}\left[\mathrm{U}^{15} \mathrm{~N}\right] \mathrm{A} \beta(1-40)$ at $37^{\circ} \mathrm{C}$ for 3 days in $10 \mathrm{mM}$ potassium phosphate buffer ( $\mathrm{pH}$ 7.4).

\subsection{CAP Irradiation}

We performed irradiation of He atmospheric cold plasma using two different laboratorybuilt apparatuses [26-28]. [U- $\left.{ }^{15} \mathrm{~N}\right] \mathrm{A} \beta(1-40)$ was dissolved at a concentration of $0.1 \mathrm{mM}$ in $10 \mathrm{mM}$ potassium phosphate buffer ( $\mathrm{pH}$ 7.4). In the apparatus primarily used in this study, the calculated mean input power was $8.0 \mathrm{~W}$ and moist He with $100 \%$ relative humidity 
served as the source gas, with a flow rate of $3 \mathrm{~L} / \mathrm{min}$ through the dielectric tube regulated by a mass flow controller $[26,27]$. When the timer-controlled high-voltage power supply (with a frequency of $10 \mathrm{kHz}$ ) of this system was turned on, He atmospheric cold plasma was generated and it flowed out from the nozzle of the glass tube of $2 \mathrm{~mm}$ diameter (Figure 1). In the other apparatus, the calculated mean input power was $1.0 \mathrm{~W}$, and He gas was supplied with a flow rate of $3 \mathrm{~L} / \mathrm{min}$ through a copper pipe attached to the Peltier device (LVPU-30; VICS, Tokyo, Japan) [28]. The generated plasma was applied for irradiation to A $\beta(1-40)$ or buffer solution in a glass-base dish for 10-30 s. A $250 \mu \mathrm{L}$ aliquot in a $\varphi 12-\mathrm{mm}$ dish (IWAKI, Fukushima, Japan) was subjected to the $8.0 \mathrm{~W}$ plasma jet at room temperature, whereas a $200 \mu \mathrm{L}$ aliquat in a $\varphi 10 \mathrm{~mm}$ dish (MatTek, Ashland, MA, USA) was subjected to the $1.0 \mathrm{~W}$ plasma jet at $30^{\circ} \mathrm{C}$. Unless otherwise stated, the results presented in this paper are based on the $8.0 \mathrm{~W}$ plasma jet apparatus.

The $\mathrm{H}_{2} \mathrm{O}_{2}$ concentration in the solution after CAP irradiation was estimated using a colorimetric staining probe (WAK- $\mathrm{H}_{2} \mathrm{O}_{2} ;$ Kyoritsu Chemical-Check Laboratory, Yokohama, Japan) in the presence and absence of $100 \mu \mathrm{g} / \mathrm{mL}$ of catalase.

\subsection{NMR Experiments}

NMR spectral measurements were made on a Bruker DMX-500 spectrometer equipped with a cryogenic probe (Bruker, Billerica, MA, USA). ${ }^{1} \mathrm{H}-{ }^{15} \mathrm{~N}$ HSQC spectra were measured at $5{ }^{\circ} \mathrm{C}$ with $0.1 \mathrm{mM}[\mathrm{U}-15 \mathrm{~N}] \mathrm{A} \beta(1-40)$ solution with $5 \%(v / v){ }^{2} \mathrm{H}_{2} \mathrm{O}$ with and without pretreatment with CAP or in the presence and absence of varying amounts of $\mathrm{H}_{2} \mathrm{O}_{2}$. The samples were stored at $37^{\circ} \mathrm{C}$ during time-course NMR measurements.

\subsection{HPLC Analyses}

The $A \beta(1-40)$ samples with and without plasma irradiation were analyzed by the HPLC system (Shimazu, Kyoto, Japan) using a reverse-phase C18 column (Sunniest C18; ChromaNik Technologies Inc., Osaka, Japan) with a water:acetonitrile- $0.1 \%(v / v)$ trifluoroacetic acid gradient at a flow rate of $1.0 \mathrm{~mL} / \mathrm{min}$. Each fraction containing $\mathrm{A} \beta(1-40)$ was collected and lyophilized for subsequent analyses.

\subsection{MS Analyses}

The determination of the molecular weight of $A \beta(1-40)$ was performed using MALDITOF-MS. The samples were mixed with the 2,5-dihydroxy-benzoic acid (DHBA) matrix solution and then detected by a MALDI-TOF high-resolution mass spectrometer (microflex LRF; Bruker Daltonics, Billerica, MA, USA) under negative ion mode.

LC-MS/MS analysis was performed on the lyophilized fractions of $\left[\mathrm{U}-{ }^{13} \mathrm{C},{ }^{15} \mathrm{~N}\right] \mathrm{A} \beta$ (1-40), separated by a reverse-phase C18 column (Sunniest C18; ChromaNik Technologies Inc.). The lyophilized powder was dissolved in $40 \mathrm{mM} \mathrm{NH}_{4} \mathrm{HCO}_{3} / 10 \%(v / v)$ acetonitrile and incubated with trypsin (MS-grade Trypsin Gold; Promega, Madison, WI, USA) at $37^{\circ} \mathrm{C}$ for $2 \mathrm{~h}$. MS spectra were acquired using a LC-MS (SCIENTIFIC Orbitrap Elite; Thermo Fisher Scientific, Waltham, MA, USA). The MS/MS data were acquired and processed using the MassLynx software (Waters, Milford, MA, USA), and MASCOT (Matrix Science, London, UK) was used to search the database.

\subsection{ThT Assay}

$\mathrm{A} \beta(1-40)(0.1 \mathrm{mM})$ and $\mathrm{A} \beta(1-42)(0.05 \mathrm{mM})$ solutions were supplemented with $200 \mu \mathrm{M}$ ThT from a $2 \mathrm{mM}$ stock solution. Each sample was then pipetted into the multiple wells of a 96-well half-area, low-binding polyethylene glycol coating plate (Corning 3881) with a clear bottom, at $80 \mu \mathrm{L}$ per well, followed by incubation at $37^{\circ} \mathrm{C}$ under quiescent conditions in a plate reader (Infinite 200Pro; TECAN, Zurich, Switzerland). The ThT fluorescence was measured through the bottom of the plate with a $430 \mathrm{~nm}$ excitation filter and a $485 \mathrm{~nm}$ emission filter. The ThT fluorescence was followed for three repeats of each sample. 


\subsection{TEM}

Amyloid fibrils of $A \beta(1-40)$ proteins were subjected to negative stain EM analyses. Briefly, the specimens stained with $2 \%$ uranyl acetate on the grid were observed with a $80 \mathrm{kV}$ electron microscope (JEM-1010; JEOL Inc., Tokyo, Japan). The fibril images were collected at a nominal magnification of $100,000 \times$.

\section{Conclusions}

In the present study based on NMR, MS, and kinetics analyses, we clearly demonstrated that the CAP irradiation results in selective oxidation of Met35 of A $\beta(1-40)$, which suppresses amyloid fibril formation. This modification is made by reactive oxygen species generated in the plasma-irradiated buffer solution, rather than by the direct action of the plasma. Indeed, our results are in qualitative agreement with experiments in which $\mathrm{H}_{2} \mathrm{O}_{2}$ was used for oxidation of $A \beta$, which strongly suggests that $\mathrm{H}_{2} \mathrm{O}_{2}$ is a potent candidate responsible for the $A \beta$ oxidation and the consequent inhibition of its fibril formation. We also suggest that the degradation of $A \beta$ fibrils on CAP irradiation is, at least partially, ascribed to $\mathrm{H}_{2} \mathrm{O}_{2}$-mediated Met35 oxidation. It has been reported that the oligomer formation of $A \beta$ is attenuated by methionine oxidization [29] and the methionine oxidized form of $A \beta$ has low toxicity $[30,31]$. Therefore, it can be expected that $A \beta(1-40)$ prepared by plasma irradiation is also less toxic. The elucidation of the molecular mechanisms behind the effects of plasma irradiation on amyloid formation provide fundamental insights into plasma biology, giving clues for developing novel applications of CAP in the fields of materials and medical sciences.

Supplementary Materials: Supplementary materials can be found at https://www.mdpi.com/1422 $-0067 / 22 / 6 / 3116 /$ s1.

Author Contributions: Conceptualization, M.Y.-U. and K.K.; sample preparation and NMR experiment, M.Y.-U.; plasma experiment, M.Y.-U., T.T., Y.O., A.Y., S.Y. and M.N.; writing—original draft preparation, M.Y.-U. and K.K. All authors have read and agreed to the published version of the manuscript.

Funding: This work was supported in part by Plasmabio Consortium (Grant Number 01221910 and 01222006), by JSPS KAKENHI (Grant Number JP19K07041 to M.Y.-U.).

Data Availability Statement: The data presented in this study are available on request from the corresponding author.

Acknowledgments: We are grateful for Weontae Lee (Yonsei University) for useful discussions. We would like to thank Shota Sasaki and Toshiro Kaneko (Tohoku University) for designing and providing the CAP irradiation system. Yukiko Isono (IMS) for help in preparing recombinant proteins, and Atsuko Nakade (NIBB) for help in the CAP irradiation. We also thank Functional Genomics Facility, NIBB Core Research Facilities and Instrument Center, Institute for Molecular Science, for technical support.

Conflicts of Interest: The authors declare no conflict of interests.

\section{References}

1. Bernhardt, T.; Semmler, M.L.; Schäfer, M.; Bekeschus, S.; Emmert, S.; Boeckmann, L. Plasma Medicine: Applications of Cold Atmospheric Pressure Plasma in Dermatology. Oxidative Med. Cell. Longev. 2019, 2019, 1-10. [CrossRef]

2. Braný, D.; Dvorská, D.; Halašová, E.; Škovierová, H. Cold Atmospheric Plasma: A Powerful Tool for Modern Medicine. Int. J. Mol. Sci. 2020, 21, 2932. [CrossRef]

3. Liu, P.; Wang, G.; Ruan, Q.; Tang, K.; Chu, P.K. Plasma-activated interfaces for biomedical engineering. Bioact. Mater. 2021, 6, 2134-2143. [CrossRef] [PubMed]

4. $\quad$ Attri, P.; Kumar, N.; Park, J.H.; Yadav, D.K.; Choi, S.; Uhm, H.S.; Kim, I.T.; Choi, E.H.; Lee, W. Influence of reactive species on the modification of biomolecules generated from the soft plasma. Sci. Rep. 2015, 5, srep08221. [CrossRef]

5. Choi, S.; Attri, P.; Lee, I.; Oh, J.; Yun, J.-H.; Park, J.H.; Choi, E.H.; Lee, W. Structural and functional analysis of lysozyme after treatment with dielectric barrier discharge plasma and atmospheric pressure plasma jet. Sci. Rep. 2017, 7, 1-10. [CrossRef] [PubMed] 
6. Attri, P.; Han, J.; Choi, S.; Choi, E.H.; Bogaerts, A.; Lee, W. CAP modifies the structure of a model protein from thermophilic bacteria: Mechanisms of CAP-mediated inactivation. Sci. Rep. 2018, 8, 1-10. [CrossRef] [PubMed]

7. Attri, P.; Park, J.-H.; De Backer, J.; Kim, M.; Yun, J.-H.; Heo, Y.; Dewilde, S.; Shiratani, M.; Choi, E.H.; Lee, W.; et al. Structural modification of NADPH oxidase activator (Noxa 1) by oxidative stress: An experimental and computational study. Int. J. Biol. Macromol. 2020, 163, 2405-2414. [CrossRef] [PubMed]

8. Takai, E.; Kitamura, T.; Kuwabara, J.; Ikawa, S.; Yoshizawa, S.; Shiraki, K.; Kawasaki, H.; Arakawa, R.; Kitano, K. Chemical modification of amino acids by atmospheric-pressure cold plasma in aqueous solution. J. Phys. D Appl. Phys. 2014, $47,285403$. [CrossRef]

9. Bayliss, D.L.; Walsh, J.L.; Shama, G.; Iza, F.; Kong, M.G. Reduction and degradation of amyloid aggregates by a pulsed radio-frequency cold atmospheric plasma jet. New J. Phys. 2009, 11, 115024. [CrossRef]

10. Schmidt, M.; Sachse, C.; Richter, W.; Xu, C.; Fandrich, M.; Grigorieff, N. Comparison of Alzheimer A $\beta$ (1-40) and A $\beta$ (1-42) amyloid fibrils reveals similar protofilament structures. Proc. Natl. Acad. Sci. USA 2009, 106, 19813-19818. [CrossRef] [PubMed]

11. Yagi-Utsumi, M.; Matsuo, K.; Yanagisawa, K.; Gekko, K.; Kato, K. Spectroscopic Characterization of Intermolecular Interaction of Amyloid $\beta$ Promoted on GM1 Micelles. Int. J. Alzheimer's Dis. 2010, 2011, 925073.

12. Matsuzaki, K.; Kato, K.; Yanagisawa, K. A $\beta$ polymerization through interaction with membrane gangliosides. Biochim. Biophys. Acta 2010, 1801, 868-877. [CrossRef] [PubMed]

13. Tycko, R.; Wickner, R.B. Molecular Structures of Amyloid and Prion Fibrils: Consensus versus Controversy. Acc. Chem. Res. 2013, 46, 1487-1496. [CrossRef] [PubMed]

14. Schmidt, M.; Rohou, A.; Lasker, K.; Yadav, J.K.; Schiene-Fischer, C.; Fandrich, M.; Grigorieff, N. Peptide dimer structure in an A $\beta$ (1-42) fibril visualized with cryo-EM. Proc. Natl. Acad. Sci. USA 2015, 112, 11858-11863. [CrossRef] [PubMed]

15. Watanabe-Nakayama, T.; Ono, K.; Itami, M.; Takahashi, R.; Teplow, D.B.; Yamada, M. High-speed atomic force microscopy reveals structural dynamics of amyloid $\beta 1-42$ aggregates. Proc. Natl. Acad. Sci. USA 2016, 113, 5835-5840. [CrossRef]

16. Meier, B.H.; Riek, R.; Böckmann, A. Emerging Structural Understanding of Amyloid Fibrils by Solid-State NMR. Trends Biochem. Sci. 2017, 42, 777-787. [CrossRef]

17. Matsuzaki, K.; Kato, K.; Yanagisawa, K. Ganglioside-Mediated Assembly of Amyloid $\beta$-Protein: Roles in Alzheimer's Disease. Prog. Mol. Biol. Transl. Sci. 2018, 156, 413-434.

18. Yagi-Utsumi, M. NMR Characterization of Conformational Dynamics and Molecular Assemblies of Proteins. Biol. Pharm. Bull. 2019, 42, 867-872. [CrossRef]

19. Itoh, S.G.; Yagi-Utsumi, M.; Kato, K.; Okumura, H. Effects of a Hydrophilic/Hydrophobic Interface on Amyloid- $\beta$ Peptides Studied by Molecular Dynamics Simulations and NMR Experiments. J. Phys. Chem. B 2019, 123, 160-169. [CrossRef]

20. Yagi-Utsumi, M.; Yanaka, S.; Song, C.; Satoh, T.; Yamazaki, C.; Kasahara, H.; Shimazu, T.; Murata, K.; Kato, K. Characterization of amyloid $\beta$ fibril formation under microgravity conditions. NPJ Microgravity 2020, 6, 17. [CrossRef]

21. Hiller, K.-O.; Masloch, B.; Gobl, M.; Asmus, K.-D. Mechanism of the OH• Radical Induced Oxidation of Methionine in Aqueous Solution. J. Am. Chem. Soc. 1981, 103, 2734-2743. [CrossRef]

22. Anzai, K.; Aoki, T.; Koshimizu, S.; Takaya, R.; Tsuchida, K.; Takajo, T. Formation of reactive oxygen species by irradiation of cold atmospheric pressure plasma jet to water depends on the irradiation distance. J. Clin. Biochem. Nutr. 2019, 64, 187-193. [CrossRef]

23. Hou, L.; Shao, H.; Zhang, Y.; Li, H.; Menon, N.K.; Neuhaus, E.B.; Brewer, J.M.; Byeon, I.J.; Ray, D.G.; Vitek, M.P.; et al. Solution NMR studies of the $\mathrm{Ab}(1-40)$ and $\mathrm{Ab}(1-42)$ peptides establish that the Met35 oxidation state affects the mechanism of amyloid formation. J. Am. Chem. Soc. 2004, 126, 1992-2005. [CrossRef]

24. Gu, M.; Viles, J.H. Methionine oxidation reduces lag-times for amyloid-b(1-40) fiber formation but generates highly fragmented fibers. Biochim. Biophys. Acta 2016, 1864, 1260-1269. [CrossRef]

25. Razzokov, J.; Yusupov, M.; Bogaerts, A. Oxidation destabilizes toxic amyloid $\beta$ peptide aggregation. Sci. Rep. 2019, 9, 1-7. [CrossRef]

26. Sasaki, S.; Kanzaki, M.; Kaneko, T. Calcium influx through TRP channels induced by short-lived reactive species in plasmairradiated solution. Sci. Rep. 2016, 6, 25728. [CrossRef]

27. Sasaki, S.; Hokari, Y.; Kumada, A.; Kanzaki, M.; Kaneko, T. Direct plasma stimuli including electrostimulation and OH radical induce transient increase in intracellular Ca2+and uptake of a middle-size membrane-impermeable molecule. Plasma Process. Polym. 2018, 15, 1700077. [CrossRef]

28. Yoshimura, S.; Aramaki, M.; Otsubo, Y.; Yamashita, A.; Koga, K. Controlling feeding gas temperature of plasma jet with Peltier device for experiments with fission yeast. Jpn. J. Appl. Phys. 2019, 58, SEEG03. [CrossRef]

29. Palmblad, M.; Westlind-Danielsson, A.; Bergquist, J. Oxidation of methionine 35 attenuates formation of amyloid $\beta$-peptide 1-40 oligomers. J. Biol. Chem. 2002, 277, 19506-19510. [CrossRef] [PubMed]

30. Johansson, A.S.; Bergquist, J.; Volbracht, C.; Paivio, A.; Leist, M.; Lannfelt, L.; Westlind-Danielsson, A. Attenuated amyloid- $\beta$ aggregation and neurotoxicity owing to methionine oxidation. Neuroreport 2007, 18, 559-563. [CrossRef] [PubMed]

31. Carelli-Alinovi, C.; Misiti, F. Methionine 35 sulphoxide reduces toxicity of A $\beta$ in red blood cell. Eur. J. Clin. Investig. 2017, 47, 314-321. [CrossRef] [PubMed] 